\title{
Distant Blocking of Celestial Lines of Communications Using Electromagnetic Pulse
}

\author{
Mark Dmytryszyn ${ }^{1} \&$ Matthew Crook $^{1}$ \\ ${ }^{1}$ Space Systems Academic Group, Naval Postgraduate School, Monterey, USA \\ Correspondence: Timothy Sands, Department of Mechanical Engineering (CVN), Columbia University, New \\ York, NY 10027, USA. Tel: 1-831-656-3954. E-mail: dr.timsands@caa.columbia.edu
}

Received: April 1, 2020

doi:10.5539/apr.v12n4p92
Accepted: June 1, 2020

Online Published: July 31, 2020

\begin{abstract}
The potentially imminent and existential threat from a nuclear electromagnetic pulse are arguably inflated, voiced to garner attention to the true issue, that today's microelectronics are incredibly vulnerable to electromagnetic damage caused by sudden voltage spikes from the electromagnetic pollution. Additionally, a nuclear electromagnetic pulse does not need to be detonated in outer space to cause signification disruption to communications systems' data and information flow across the celestial domain. High altitude electromagnetic pulse (HEMP) detonations do not need to occur in outer space to have wide ranging effects; in describing electromagnetic pulses, the high-altitude moniker is tied to any detonation above nineteen miles (thirty point-five kilometers). High altitude electromagnetic pulse detonations ranging from fifty to one hundred kilometers can project wave effects into outer space and affect spacecraft through both direct damage (contemporary views regarding electromagnetic pulse) and radiation-induced torques on the solar arrays, misaligning satellite antennas and sensors. If an actor - state or otherwise - wished to compete or contest another along the congested celestial lines of communications (CLOCs), it can be done at great distance from the affected entity by use of a high altitude electromagnetic pulse on the 'far side' of the orbit. Additionally, the historic maritime tactic of blockade has applicability in space; yesterday's ships are today's gamma ray damage to microelectronics. Furthermore, the employment of a nuclear weapon-delivered high-altitude electromagnetic pulse remains a treaty violation, for those who are a party to. However, greater jurisprudence study is lacking regarding this matter, and the accompanying concern of transboundary harm as it relates to territorial sovereignty. In summary, an actor can contest another's use of the celestial lines of communications by detonating a nuclear weapon, at high-altitude but within the atmosphere (i.e., below one hundred kilometers), and within the lateral boundaries of their sovereign territory and associated territorial waters, and allow wave's effects to radiate widely to interrupt operations and possibly inflict permanent damage, all without being in violation of treaty or customary law. This manuscript substantiates the prequel baseline for follow-on research on mitigation of the deleterious effects on communication system circuits in attempts to void the blockage on celestial lines of communications, and the sequel is briefly introduced with a short description of the state-of-the-art research.
\end{abstract}

Keywords: Blocking, Electromagnetic Pulse, Electromagnetic Pollution, Nuclear Weapon, High Altitude Electromagnetic Pulse, Deterministic Artificial Intelligence, Van Der Pol Equation, Forced Van Der Pol Equation, Communication Systems, Timing Circuits

Even before the Trinity nuclear test in July of 1945, physicists predicted a transient electromagnetic signal would be caused by high-energy photons released from the detonation interacting with the air around the detonation.J. Morrow-Jones (Morrow-Jones, 2019)

\section{Introduction}

\subsection{Fictional Vignette}

Tensions on the Korean Peninsula rise as a US-led coalition and North Korea climb the escalation ladder (Yeaw, 2015). As a show of resolve, time the North Korean leadership display an Uhna-3 (Taepodong-3) missile and message they will launch an early warning and surveillance satellite. Unbeknownst to those outside of North Korea, the weapon is topped with a nuclear warhead estimated to produce a one hundred forty kiloton yield. According to U.S. intelligence assessments, the September 3, 2017 North Korean nuclear test weapon produced an estimated one hundred forty kiloton yield (Nuclear Threat Initiative, "North Korea Nuclear," NTI.org, 2018). The missile 
launches, and flying an eastward trajectory, the weapon detonates at three hundred miles (four hundred eighty-five kilometers) over Kansas, causing a blackout affecting nearly the entire continental United States (Nakatani \& Sands, 2018). A significant number of satellites are damaged, ranging from internet and television providers to national nuclear command and control (Sands, Camacho, \& Mihalik, 2018a, 2018b). Several corporations file liability claims against North Korea at The Hague. While the world moves on, it does so having experienced the unlikely - a high-altitude electromagnetic pulse.

\subsection{Description of the Problem}

With this brief motivational vignette (realistic (Nakatani \& Sands, 2018; Timmerman, 2001) yet nonetheless fictional), this manuscript describes electromagnetic pulse detonations, provides a detailed description and characterization of electromagnetic pulse waves and their effects at various distances. The manuscript briefly describes the high-altitude physical environment and provides a brief legal context (Sands \& Mihalik, 2016) for using these effects to intentionally interfere with communications, returning to the opening fictional vignette to maintain realistic context for application. Lastly, the manuscript launches from this baseline understanding to fathom future research seeking to mitigate the deleterious effects. Very brief mathematical articulation of communication timing circuits is augmented with recent application of deterministic artificial intelligences to increase communication system robustness in the event of a high-altitude nuclear detonation produced electromagnetic pulse.

\subsection{Scope of Relevant Scholarship}

For the sake of space, and with an appreciation of the likely reader's familiarity with the material, this treatment provides only a brief review of the electromagnetic pulse phenomenon. Moreover, it limits the discussion to electromagnetic pulse produced by a generic nuclear weapon, not one from something 'tuned' to enhance electromagnetic pulse effects nor from a non-nuclear electromagnetic pulse-generating weapon (e.g., a high-power microwave). Furthermore, some devices are developed to absorb the radiation from the wireless devices, metamaterial being one of them metamaterial structure and absorption phenomena of electromagnetic radiations are mentioned for future research alongside circuits designed to mitigate effect absorption.

\section{Method}

The Method section describes in detail how the study was conducted, including conceptual and operational definitions of the variables used in the study, Different types of studies will rely on different methodologies; however, a complete description of the methods used enables the reader to evaluate the appropriateness of your methods and the reliability and the validity of your results, It also permits experienced investigators to replicate the study, If your manuscript is an update of an ongoing or earlier study and the method has been published in detail elsewhere, you may refer the reader to that source and simply give a brief synopsis of the method in this section.

\subsection{Setting Some Boundaries}

This analysis explores electromagnetic pulse-generating detonations in the high reaches of the atmosphere (endoatmospheric) and not the traditional in-space exo-atmospheric. "[T]here is no legal definition of where the regime of airspace ends, and the regime of outer space begins." (Karzas \& Latter, 1962) The commonly cited threshold is one hundred kilometers (sixty-two statute miles, fifty-four nautical miles). That limitation requires a delineation between endo- and exo-atmospheric. For this treatment, one hundred kilometers will serve as the line between air space (endo) and outer space (exo) (Koplow, 2020). Additionally, endo-atmospheric high-altitude electromagnetic pulse will be defined as a nuclear detonation above approximately nineteen miles (thirty point-five kilometers) and yet within the atmosphere. Thirty kilometers has been recognized by North Korea as the minimum altitude to achieve a "strong electromagnetic pulse generated from nuclear bomb explosion" (University of Adelaide, "The Woomera Manual (/WOOMERA/)", 2018; The Wommera Manual, University of Adelaide Faculty of the Professions, 2020; Blake \& Vihul, 2018) and the difference in air density below this altitude will stifle the deposition region and limit the electromagnetic pulse effect (Wilson, 2008).

\subsection{Developing the EMP Wave}

During a nuclear detonation, the exploding device emits prompt gamma $(\gamma)$ rays, from both the nuclear reaction(s) and the interaction of $\mathrm{x}$-rays with casing materials causing inelastic scattering of neutrons (Sands \& Mihalik, 2016). gamma $(\gamma)$ rays constitute roughly zero point-three percent of the explosive energy of a typical nuclear detonation, and for a high altitude electromagnetic pulse, only one hundredth of that zero point-three percent is radiated by the wave (Wilson, 2008). Each-kiloton of yield produces (one exa) rays of gamma $(\gamma)$ (seven-thousand five-hundred peta) rays with each ray having an average energy of one mega electron-volt (Wei \& Kiang, 2016). When detonated 
in the atmosphere, the gamma $(\gamma)$ rays excite air molecules and generate Compton electrons (Compton Effect, $\mathrm{n}$. d.). The Compton electrons are deflected by the Earth's geomagnetic field lines, causing them to spiral down the lines (Seiler, 1975). These spiraling, gyrating, radially accelerating Compton electrons move towards the Earth and interact with air molecules, ionizing the air. Together, the Compton electron current and the secondary current from the ionized air supply the electric field that radiates outward, forming the electromagnetic pulse wave (Wei \& Kiang, 2016; Compton Effect, n. d.). The size and shape of the electromagnetic pulse wave is dictated by the struggle between the creation of electric currents and subsequently generated magnetic fields and the creation of conductivity and related magnetic field dampening (Morrow-Jones, 2019).

As the wave travels from the burst point, it emits radio frequency (RF) energy along a broad range of frequencies and amplitudes (Raloff, 1981; Glasstone \& Dolan, 1977), energy that can be received by antennas and other conductors (Raloff, 1981). Collected energy "can then be converted into strong electric currents and high voltages (Glasstone \& Dolan, 1977)," which "wreaks its havoc by inducing staggeringly large and rapid current or voltage surges through electrically conducting materials (Raloff, 1981)." Additionally, the wave's ionizing radiation can generate electric fields in solid materials, including those in critical electronic systems (Glasstone \& Dolan, 1977). The wave's rate of onset is nearly instantaneous, attaining maximum value in roughly eighty nano-seconds (Glasstone \& Dolan, 1977), with an "intense energy field that can overload or disrupt at a distance numerous electrical systems and high technology microcircuits" (Wilson, 2008). This disruption to solid materials (Sands \& Armani, 2018) in microcircuits (Cooper, Heidlauf, \& Sands, 2017) and other sensitive electronics, caused by the electric field generated by the ionizing radiation, is called the 'system-generated' electromagnetic pulse (Glasstone $\&$ Dolan, 1977). With the pulse wave deriving from predominately gamma $(\gamma)$ and not $\mathrm{x}$-rays, the radio frequency emissions produced are of both higher frequency and greater amplitude (Nakatani \& Sands, 2018).

System-generated electromagnetic pulse affects solid materials with atoms heavier than those in air. These atoms are bombarded with both gamma $(\gamma)$ and x-rays, producing electrons by both Compton and photoelectric effects (Glasstone \& Dolan, 1977). The cascading release of electrons generates an electric field near the surface of the solid, and can generate significant damage to electronic components in systems that may operate in arenas with direct exposure to the propagating radiation (e.g., satellites, ballistic missiles) (Glasstone \& Dolan, 1977).

When evaluating pulse effects radii, one must remember that when a nuclear weapon is detonated in a dense atmosphere, the gamma $(\gamma)$ and $x$-ray radiation is significantly attenuated (absorbed), making blast and thermal effects the primary effects. When detonated in a thin atmosphere, or even the vacuum of outer space, blast and thermal effects are greatly reduced, arguably becoming insignificant. At these altitudes, the rays' propagation will suffer little attenuation, and only degrade in intensity as a function of range from the blast point (NASA, n. d.).

When a high-altitude electromagnetic pulse occurs for detonations above nineteen miles or roughly thirty kilometers, the gamma $(\gamma)$ rays propagate in the vertical both upwards towards outer space and downwards towards the ground (Mosher, 2017). See figure 1. The rays moving upwards encounter a very thin, low density atmosphere, allowing the rays to travel a great distance before being absorbed. In contrast, the rays moving downward interact with the higher density atmosphere where the interaction between the gamma $(\gamma)$ rays and the air molecules and atoms form the deposition, or source, region for the electromagnetic pulse (Glasstone \& Dolan, 1977).

The depth or 'thickness' of the source region may be up to fifty miles at the center (dependent upon height of burst) and taper to the edge, being circular in shape and with a mean altitude of twenty-five to thirty miles (again, dependent upon height of burst) (Glasstone \& Dolan, 1977). At the detonation's nadir, the source region is thickest because gamma $(\gamma)$ ray intensity decreases with distance from the burst point. Most gamma rays are absorbed in altitudes between forty and ten miles (Wilson, 2008).

In the source region, the Compton electrons generate a motion that causes the pulse to move downwards, toward the Earth. As the pulse's electric field moves towards the ground, it weakens, resulting in a strength at the surface of one-tenth to one-hundredth the field strength within the source region. However, for high-altitude bursts, the 'falling' electric field's strength remains roughly uniform over the encompassed ground area (Glasstone \& Dolan, 1977). For yields of a few hundred-kilotons, such as a likely weapon produced by North Korea, the electric field strength varies by no more than a factor of two (Wilson, 2008).

High-altitude bursts have more electromagnetic energy in the higher frequencies than for surface or near-surface bursts. As the pulse wave's electric field propagates, the higher frequency rays extend from the burst point in all directions to a distance based on the line of sight; the lower frequencies extend beyond the horizon, for the lower frequency electromagnetic waves are able to follow the Earth's curvature (Glasstone \& Dolan, 1977). For a fiftymile (eighty kilometers) height of burst, the lower frequency rays can travel to a radius of roughly six hundred miles (Glasstone \& Dolan, 1977). For a sixty-two mile (one hundred kilometers) height of burst, the tangent point 
extends to nearly seven hundred miles (eleven hundred, twenty kilometers) (Glasstone \& Dolan, 1977).

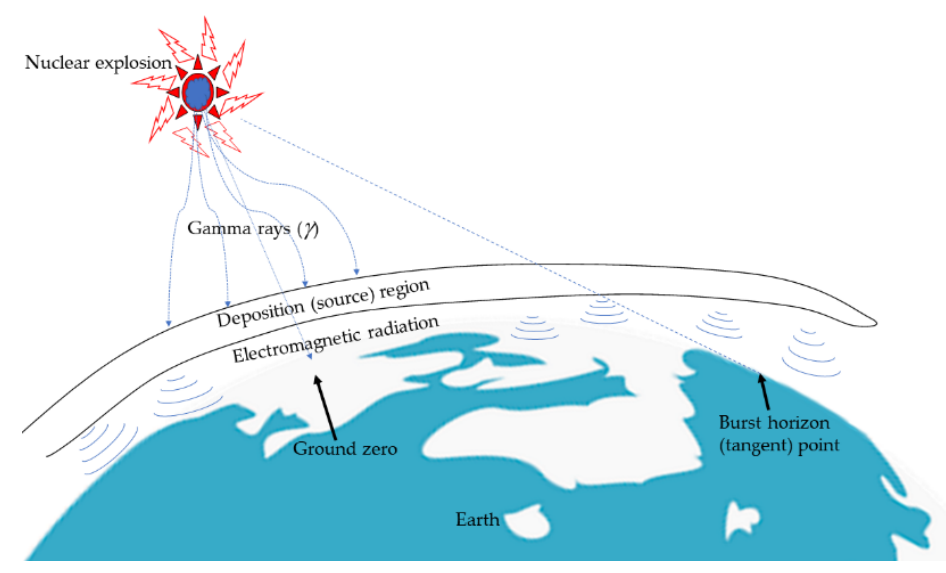

Figure 1. Representation of the electromagnetic pulse in a high-altitude nuclear burst

\subsection{Characterizing the Electromagnetic Pulse Wave - E1, 2, 3}

For a high-altitude electromagnetic pulse illustrated in figure 2 (Ministry of Defence: Electromagnetic Pulse Protection Modules, n. d.), the pulse wave's effects are addressed with respect to time of arrival: an early time (E1), an intermediate time (E2), and a late time (E3). The E1 period's effects - sometimes called the 'prompt' field effects - are caused by the prompt gamma $(\gamma)$ rays from the detonation interacting with high-altitude air molecules. The E2 period is bifurcated into an early part, E2A - which is a continuation of the E1 effects period - and E2B with effects caused by delayed gamma $(\gamma)$ rays and high-energy scattered neutrons interacting with the atmosphere. The E3 period is also bifurcated, but here the split is not based on time; rather, it is based on the height of burst for the detonation. For burst altitudes above roughly two hundred fifty kilometers (one hundred fifty-five miles), an effect labeled E3A ("blast") addresses the detonation's debris pushing against the Earth's geomagnetic field. E3B ("heave") is caused by x-rays and kinetic energy heating ionizing the atmosphere, causing it to become buoyant and rise. The rising atmosphere combines with the heated ionization, causing the ions to be 'pulled' across geomagnetic field lines. The E3 period's effects are dominated by "the magnetohydrodynamics (MHD) of energetic plasmas interacting with the earth's geomagnetic field," a discussion left to others (Morrow-Jones, 2019; Commission to Assess the Threat to the United States from Electromagnetic Pulse Attack Washington United States, 2017)).

For high-altitude bursts, the three effects occur with disparate times and disparate impacts and can aggregate to cause (sometimes cripplingly) damage to microelectronics (Wilson, 2008). Even when not crippling, the effects can disrupt timing circuits in communications systems. The E1 effects' amplitude peaks at tens of kilovolts per meter $(\mathrm{kVm}-1)$ within a few nanoseconds, with effects lasting for a few hundred nanoseconds and generating currents in the kilo-amperes range. A one hundred kiloton yield weapon detonated at eighty and sixty-five kilometers, would generate peak E1 electric field effects of thirty-four and thirty-six kilo volt per meter, respectively. If the detonation occurred in the northern hemisphere, the peak would be oriented towards the south; the reverse is true to a detonation in the southern hemisphere (Klein, 2006).

The E1 effect is broad spectrum, emitting across a frequency band in the tens-to-hundreds of megahertz. This broad frequency spectrum enables the wave to couple to microelectronics without penetrating via a cable or antenna, causing systems within line-of-sight to receive damage ranging from upset and overloaded to permanent (Commission to Assess the Threat to the United States from Electromagnetic Pulse Attack Washington United States, 2017).

The E2 effects' amplitude peaks at hundreds of volts per meter, with the effects lasting from microseconds-tomilliseconds. E2 effect manifests like that of lightening (Commission to Assess the Threat to the United States from Electromagnetic Pulse Attack Washington United States, 2017). However, the effect's rise time is three times that of lightning, and thus outstrips most lightening arrestor and protection measures, flashing through the circuit and causing damage to presumed protected systems (Raloff, 1981). Insulator flashover would not protect against electromagnetic pulse (Wilson, 2008). During Soviet nuclear detonation tests above their site in south central Asia, scientists and engineers observed "surge arrestor burnout, spark-gap breakdown, blown fuses, and power supply 
breakdowns (Graham, 2008)."

The E3 effects' remain driven by changes to the Earth's immediate geomagnetic field, making long-line conductors (lengths of a few kilometers or greater) more susceptible to damage, and by direct connection, associated electrical components (e.g., electrical grid components attached to transmission lines, copper and fiber-optic components in longline communications systems) (Electromagnetic Pulse: Effects on the U.S. Power Grid, n. d.; United States Government Accountability Office, n. d.; Testimony of Dr. George H. Baker, Senior Advisor to the Congressional EMP Commission at the June 22, 2017 Reliability Technical Conference before the Federal Energy Regulatory Commission, 2017). The $\mathrm{E} 3$ effect generates $10^{2}$ to $10^{3}$ amperes of current with effects lasting from a microsecond to many seconds. Because this effect requires the heating and expansion of the Earth's atmosphere, this effect takes much longer to materialize, and is referred to as the "late-time" power surge. The lengthy development of this period's effects allow for greater damage due to overloads that require the collection of disruptive currents and voltages (Wilson, 2008; Commission to Assess the Threat to the United States from Electromagnetic Pulse Attack Washington United States, 2017).

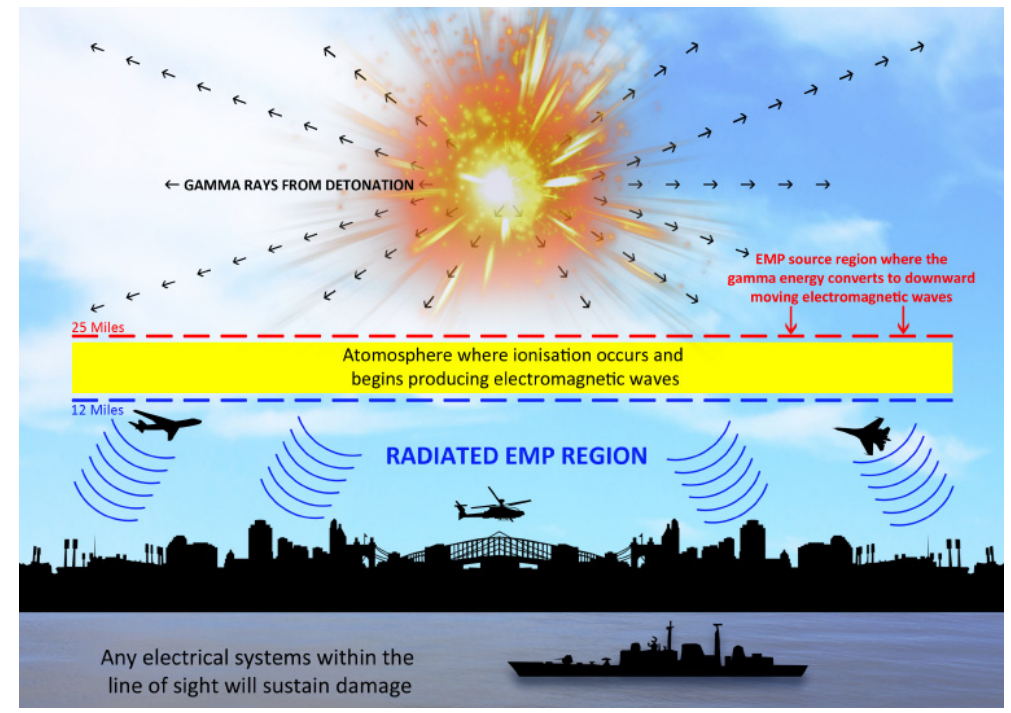

Figure 2. Representation of the electromagnetic pulse in a High-Altitude Burst

In characterizing the entire high-altitude electromagnetic pulse-generated field, Dolan and Glasstone (Glasstone, 2009) offers a general rule that the field strength may be expected to be in the tens of kilovolts per meter throughout the coverage area. Electromagnetic pulse field strengths on the ground can reach fifty kilovolts per meter (Raloff, 1981). For E1 effects, field saturation at around fifty kilovolts per meter occurs for weapons yields above one hundred kiloton (Klein, 2006). For weapon yields of a few hundred-kilotons or more, local peak field strengths (Table 1) vary as a function of distance from the burst point (listed in multiples of height of burst), and fraction of the maximum field strength, Emax. For detonations in the northern hemisphere between thirty- and sixty-degrees north latitude, local field strengths are greatest immediately south of the burst point or designated ground zero (DGZ) (Glasstone \& Dolan, 1977).

Table 1. Peak E-Field Strength Related to Distance from Burst Point

\begin{tabular}{ll}
\hline Distance from burst point & Peak Field Strength as a Fraction of Emax \\
\hline Ground zero to tangent point & 0.50 \\
2x to 4x height of burst south of the burst & 0.75 \\
2x height of burst directly south of the burst & 1.00 \\
\hline
\end{tabular}

The shape of the pulse wave's effects field is affected by more than the detonation location (hemispherical). See figure 3 (Morrow-Jones, 2019). For endo-atmospheric bursts, air density significantly impacts the E1 period of the wave's propagation (Nominal High-Altitude Electromagnetic Pulse (HEMP) Waveforms, 2019). For a height of burst of twenty kilometers, the higher air density below the point of detonation forces the strongest E1 effects upward; for thirty kilometers height of burst, the strongest E1 effects propagate laterally. Strong E1 effects are not 
observed on the ground until the height of burst increases beyond fifty kilometers, and steadily increase as the height of burst rises to ninety kilometers. For lower yield detonations, E1 effects may not be observed on the ground as the gamma $(\gamma)$ ray intensity is insufficient to penetrate the conversion layer typically between twenty kilometers and forty kilometers (Electromagnetic Pulse: Effects on the U.S. Power Grid, n. d.). If approached with devious intent, one might look to maximize the E1 effects field on the ground. For a nominal one hundred-kiloton yield, the maximum on ground E1 field occurs at a height of burst of sixty kilometers; for a one thousand-kiloton (one megaton) yield, the maximum on ground E1 field occurs at a height of burst of ninety kilometers (Electromagnetic Pulse: Effects on the U.S. Power Grid, n. d.). Synthesizing the last few paragraphs, each weapon yield has an optimal height of burst, as well as an angle from nadir pointing to the south or north (hemispheredependent) that maximizes the high-altitude electromagnetic pulse-driven E1 effects on the ground. A one hundred-kiloton yield generates an Emax of thirty-six kilovolts per meters (with rise time of three nanoseconds) at a height of burst of sixty-seven kilometers. A three-hundred-kiloton yield generates an Emax of forty-six kilovolts per meter (with rise time of three-nanoseconds) at a height of burst of seventy-seven kilometers (Electromagnetic Pulse: Effects on the U.S. Power Grid, n. d.). The significance of these yields and height of bursts will be revealed shortly.

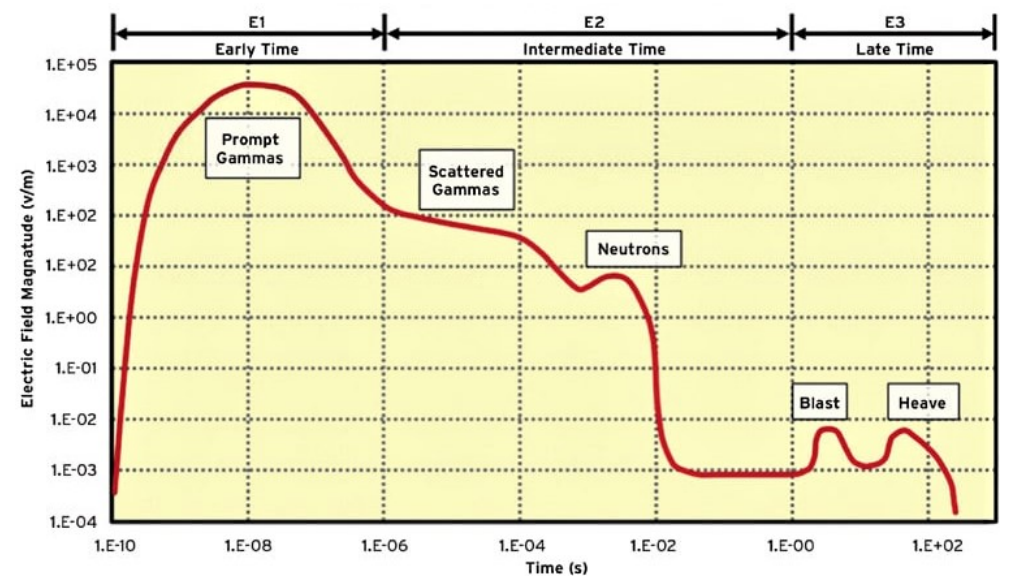

Figure 3. Example timescales for a notional high-altitude electromagnetic pulse

\section{Results}

After a brief motivational vignette in the Introduction, this manuscript described electromagnetic pulse detonations, and provided a detailed description and characterization of electromagnetic pulse waves and their effects at various distances. The next section of this manuscript briefly describes the high-altitude physical environment and provided a brief legal context for using these effects to intentionally interfere with communications, returning to the opening fictional vignette to maintain realistic context for application. Afterwards, the following section launches from this baseline understanding to fathom future research seeking to mitigate the deleterious effects. Very brief mathematical articulation of communication timing circuits is augmented with recent application of deterministic artificial intelligences to increase communication system robustness in the event of a high-altitude nuclear detonation produced electromagnetic pulse.

\subsection{Endo-Atmospheric Versus exo-Atmospheric: The Edge of Space}

Section 2 limited analysis to electromagnetic pulse-driven detonations within the atmosphere, not in space. That stipulation is significant, as there is a limit to a nation's vertical sovereignty with outer space not being subject to national appropriation (Klein, 2006). That is for good reason - outer space's value comes from its open access and growing utility, and with that the ability to transport physical and electronic matters across celestial lines of communications (Klein, 2006). The term "space communications' refers to the overall activity of communicating into, from, and through space, while 'celestial lines of communications' refers to the routes used for such activities." (Klein, 2006) And while a state retains sovereignty over its territory (including territorial waters extending to twelve nautical miles from shore), to include the airspace above, it does not have special legal rights above that airspace (Koplow, 2020). Sovereignty over a state's airspace was established by the Chicago Convention on Civil Aviation, Article 1. A state's airspace extends vertically from the edges of its territory (including territorial waters) to the upper most limits of airspace. However, sovereignty does not extend to airspace over any Exclusive Economic Zone (EEZ) (Joint Chiefs of Staff, Joint Publication 3-14: Space Operations, 2018). Simply put, a state 
does not have sovereignty over its territory in outer space. Thus, the definition of the boundary between the atmosphere and space is vital.

\subsubsection{Defining the Start of Outer Space - The Kármán Line}

Kármán line, the demarcation between air space and outer space (between endo-atmospheric and exo-atmospheric). While there continues to be no legally binding definition for the location of this line, if there were, the United States would likely not concur as it may limit current and future opportunities. Presently, the United States has specifically resisted pressures to accept the line's placement at one hundred kilometers (sixty-two miles) (Nominal High-Altitude Electromagnetic Pulse (HEMP) Waveforms, 2019; The United Nations, Convention on the Prohibition of Military or any Hostile Use of Environmental Modification Techniques, 1977).

Through a military lens, the line is better described as the delineator between the air and the space domains. Codified in doctrine, the space domain's demarcation is as the "area above the altitude where atmospheric effects on airborne objects become negligible (Joint Chiefs of Staff, Joint Publication 3-14: Space Operations, 2018)." This again seems incomplete, more so when seeking something substantive for use in legal matters, specifically liability determinations. Therefore, Klein's sweeping description may serve to reinforce the use of one hundred kilometers (sixty-two miles) as the customarily accepted line of demarcation: If trying to define where space begins for biological reason, one might choose nine miles above the earth, since above this point a pressure suit is required. If concerned with propulsion, twenty-eight miles is important since this is the limit of air-breathing engines. For administrative purposes, one might find it important that US astronaut's wings may be earned above fifty miles. An aeronautical engineer might define space as starting at sixty-two miles above the earth's surface, since this is where aerodynamic controls become ineffective. Conventional and customary law defines the lower boundary of space as the lowest perigee of orbiting space vehicles (Klein, 2006). As the central theme begins to materialize, one should appreciate that a state's sovereignty is a large volume, and that state leadership can conduct myriad activities within that volume, to include acts that may be damaging both within and beyond the sovereign spaces. If those acts caused degradation or denial of celestial lines of communications access or conveyance, a neighboring state could be crippled economically or defensively.

\subsubsection{Outer Space and International Law}

While a number of treaties have brought pseudo-governance to space-faring nations' activities - including the lack of restrictions for spacecraft to overfly another state's territory from outer space - becoming a party to a treaty requires more than a signature; it requires the party state to ratify the treaty for adherence (to become a party to). Once a party to a treaty, that state now must abide by the language as governance. For example, if a state was a party to the Limited Test Ban Treaty, they would be in violation when conducting a nuclear explosion in the atmosphere or beyond its limits, including outer space (The United Nations, Convention on the Prohibition of Military or any Hostile Use of Environmental Modification Techniques, 1977).

A number of treaties have applicability to space activities (e.g., Outer Space Treaty, Limited Test Ban Treaty, Comprehensive Nuclear Test-Ban Treaty), with the most germane to this argument being the Space Liability Convention (The full title is The Convention on International Liability for Damage Caused by Space Objects.) which stipulates that states shoulder responsibility (liability) for all space objects launched within their territory and any damage said objects may cause (Koplow, 2020). Pertinent to this convention, 'damage' means "loss of life, personal injury or other impairment of health; or loss of or damage to property of States or of persons, natural or juridical, or property of international intergovernmental organizations (Harrington, 2020)."

The Space Liability Convention seems clear in determining liability if the source of the incident is owed to a physical object, and the damage inflicted clearly met a condition listed... and the state was a party to the convention (treaty). Open for debate is whether: (1) effects (e.g., wave effects) qualify as a space object from a jurisprudence position; (2) liability, either by this convention or by customary international law, applies to all states and actors regardless of treaty or convention ratification (Koplow, 2020); and (3) an electromagnetic pulse-generated by an endo-atmospheric act within the boundaries of a state, that caused damage, if 'transboundary harm' would serve as sufficiency to pursue remittance under customary legal practices (Harrington, 2020). In contrast, an electromagnetic pulse-generated by an exo-atmospheric act, specifically from a nuclear detonation, would likely serve as enough to pursue remittance (Nakatani \& Sands, 2018). While the gist of the liability rules may be considered customary law, interpretations by states (including the United States) have shown disregard for international law so as to not preclude military activities in space "including the ability to perform self-defense or denial measures (Klein, 2006).”

If damage liability is not a deterrent to knowingly committing damage to space objects, then consider an alternative in the United Nation's convention on environmental modification (Convention on the Prohibition of Military or 
any Hostile Use of Environmental Modification Techniques). This convention stipulates that states a party to will not engage in "environmental modification techniques having widespread, long lasting [sic], or sever effects" with environmental modification techniques include deliberate changes to the natural processes "the Earth including its biota, lithosphere, hydrosphere and atmosphere, or of outer space (The United Nations, Convention on the Prohibition of Military or any Hostile Use of Environmental Modification Techniques, 1977)." The convention considers "widespread" as impacting an area of several hundred square kilometers (Koplow, 2018). The convention expressly stipulates phenomena used in environmental modification techniques that could change the state of the ionosphere (The United Nations, Convention on the Prohibition of Military or any Hostile Use of Environmental Modification Techniques, 1977). The ionosphere ranges from seventy-five kilometers to onethousand kilometers, crossing the Kármán Line and incorporating the mesosphere, thermosphere, exobase, and roughly the lower half of low-earth orbit (LEO) altitudes.

\section{Discussion}

The Introduction of this manuscript briefly described electromagnetic pulse detonations and characterization of electromagnetic pulse waves and their effects at various distances. Methods and Materials briefly described the high-altitude physical environment and provided a brief legal context for using these effects to intentionally interfere with communications. This section launches from that baseline understanding to articulate blocking of celestial lines of communications before the Conclusions section fathoms future research seeking to mitigate the deleterious effects. Very brief mathematical articulation of communication timing circuits is augmented with recent application of deterministic artificial intelligences to increase communication system robustness in the event of a high-altitude nuclear detonation produced electromagnetic pulse.

\subsection{Exploiting Endo-Atmospheric Electromagnetic Pulse-Blocking}

As outer space remains congested, contested, and competitive (sometimes referred to as the three c's), it is ripe for states to take action that is viewed as quintessential security dilemma - protective acts taken by state A is viewed as provocative or threatening by neighboring state $\mathrm{B}$ (Koplow, 2018). Klein assesses that if state A took egregious action against state B's satellite, despite its destruction, it is doubtful state B would retaliate "because of its lack of political importance (Klein, 2006).” Arguably the attribution of state A's act on state B's satellite makes state A ripe for liability remittance. However, if state A took action that manifested as degradation or denial of the satellite's services - like what occurs during peak solar flare activity - then state A may be positioned to advance its security at the expense of state B. The prevention of state B from using its celestial lines of communications is a blockade, now employed in space, beyond its customary application in the maritime domain (Klein, 2006). Solar flares generate an "excessive amount of charged particles entering the Earth's magnetosphere, resulting in degraded space-based transmission and reception quality...if a satellite's protection proves inadequate, these charged particles can permanently damage sensitive onboard electronics (The United Nations, Convention on the Prohibition of Military or any Hostile Use of Environmental Modification Techniques, 1977)."

\subsection{Blocking Briefly Explained}

The blockade has been a tool of naval, and by extension economic, warfare for ages. Keeping a navy in their home port prevents trade and commerce (Klein, 2006). Executing a blockade, or simply blocking, allows an aggressor to gain control of a competitor's (or adversary's) lines of communications, offering a position of relative advantage; however, if too aggressive in employment, the competitor may escalate and drive the outbreak of hostilities (Klein, 2006). If found in a blocking situation, both parties may find solace in recognizing that the action may be only temporary, employed for only a specified duration, until a relative advantage is gained (Klein, 2006). Emplacing a blockade affecting outer space is likely to remain temporary, since the rotation of the Earth and the corresponding speed of orbits may be too great for terra-generated effects to have persistent effects unless permanent damage occurred.

\subsection{Blocking and Outer Space}

Terrestrial blocking addresses the movement of physical materials and communications. Celestial blocking is more applicable to digital communications - data and information. By congesting or disrupting the electromagnetic spectrum, the transmission of digital communications may be hindered (Klein, 2006). When applied to celestial distances and speeds, blocking can disrupt digital communications well away from the hubs of distribution (Klein, 2006). This is termed 'distant blocking' and is employed along an adversary's celestial lines of communications but at great distance from their primary information, communications, or command and control hub (Klein, 2006). 


\subsection{Distant Blocking by Electromagnetic Pulse Disruption}

The reliance on information transfer via celestial lines of communications by modern society cannot be understated. With the interconnected nature of global affairs, dependent on a digital infrastructure, an electromagnetic pulseinduced disruption of critical systems (specifically those of the civil sector supporting military operations) could generate impacts ranging from operationally upset to functionally inoperable. Examples include "the power grid, fuel distribution, transportation systems... as well as military communications systems which utilize the civilian infrastructure (Cooper, Heidlauf, \& Sands, 2017).” Furthermore, the lack of communications systems would doubly confound post-attack evaluations and damage recovery, including critical supply chains and other deeper system enablers (Wilson, 2008; Commission to Assess the Threat to the United States from Electromagnetic Pulse Attack Washington United States, 2017). For a modern society, striking at a "technological Achilles Heel" averts the need for direct confrontation with an adversary's military or other lever of national power (Commission to Assess the Threat to the United States from Electromagnetic Pulse Attack Washington United States, 2017). As discussed above, a high-altitude electromagnetic pulse has far-reaching effects, extending to the tangent point which can exceed a thousand kilometers. For a one hundred kilometers height of burst, the effects radius is estimated at one hundred kilometers. And as an electromagnetic pulse is arguably an 'area weapon,' delivery accuracy need not be high, nor is there a need for a reentry system if the effect is delivered by a nuclear warhead atop a ballistic missile (Commission to Assess the Threat to the United States from Electromagnetic Pulse Attack Washington United States, 2017). Additionally, damage to modern electronics requires imparting only low voltage disruptions, for today's microelectronics and solid-state components are particularly sensitive to voltage and current irregularities and disruptions (Glasstone \& Dolan, 1977). “...modern electronics....are much more vulnerable to electromagnetic pulse than the electronics exposed to STARFISH PRIME and the Kazakh nuclear tests in the year nineteen sixty-two (Koplow, 2020)." Particular to large voltage and current surges, if an electronic component directly, or via an antenna, collected a small fraction of a joule of energy delivered over the pulse lengths explained above, the likelihood of at least temporary damage is sizable. Also troubling is that an electric current can cause a spark to form and jump to an adjacent conductor, making isolated microelectronics susceptible to pulse-induced disruptions (Glasstone \& Dolan, 1977).

For on-orbit space systems, blocking effects can be enacted by additional physical means. Spacecraft are acted upon by direct and reflected radiation, usually of solar origin. That radiation imparts a pressure on the surfaces of the craft, and if large enough, can induce a torque. If the craft has a large solar array, the torques can be significant. Electromagnetic pulses can emit radiation like solar radiation, putting satellites and other craft, even at the higher altitudes (e.g., geosynchronous and geostationary) at risk to disruption from physical misalignment and expenditure of unplanned corrective energies (chemical, other) (Gordon \& Morgan, 1993). Disruptions to spaceenable communications can also be impacted by E1 and E3 electromagnetic pulse effects on ground stations, and by injecting noise (above the existing cosmic noise threshold) into both the terrestrial and on-orbit systems' antennas, transmission lines, and their connectors (Gordon \& Morgan, 1993).

\subsection{Conclusions}

Returning to the introduction's vignette, as a US-led coalition and North Korea climb the escalation ladder, this time the North Korean leadership display a Musudan missile and message they will conduct a test launch to demonstrate their resolve. The Musudan missile (Nodong-B, or BM-25, or Mirim) is assessed to carry a onethousand, two-hundred kg payload and demonstrated flying a lofted trajectory traveling four hundred kilometers in distance (staying within North Korean territory) and achieving one-thousand, four-hundred kilometers in altitude (Nuclear Threat Initiative, 2014; Nuclear Threat Initiative, 2019). Unbeknownst to those outside of North Korea, the weapon is topped with a nuclear warhead estimated to produce a one hundred forty-kiloton yield. According to U.S. intelligence assessments, the September 3, 2017 North Korean nuclear test weapon produced an estimated one-hundred forty-kiloton yield (Nuclear Threat Initiative, "North Korea Nuclear," NTI.org, 2018). Timed to reach its high-altitude electromagnetic pulse-optimized height of burst when most destructive to key celestial lines of communications craft, the missile launches and the weapon detonates below one hundred kilometers, but over North Korean territory. The North Korean missile test on April 29, 2017, which detonated at an altitude of seventy-two kilometers - the optimum height of burst for electromagnetic pulse attack by a tenkiloton warhead - would create a potentially damaging pulse field spanning a nine hundred thirty kilometers radius, $r$ in kilometers: $r=100 \sqrt{h}$. For a one hundred kilometers height of burst, the effects radius is calculated to be eleven hundred kilometers (six-hundred eighty-five miles) (Koplow, 2020). The E1 effects damage high-flying surveillance aircraft and spacecraft in low earth orbit. The E3 effects extend south over the remainder of the peninsula, doing extensive damage to South Korean critical infrastructure, but causing "few if any immediate civilian casualties." "Another more subtle limited nuclear warfare trend described by [John] Warden, most relevant 
to this research, is the attempt by adversaries to 'distinguish between nuclear use consistent with Law of Armed Conflict traditions and strikes that are far less discriminating.' This approach would be to use nuclear weapons in a way that causes few if any immediate civilian casualties and in doing so hopes to avoid the backlash of transgressing the nuclear taboo (Tannenwald, 1999, 2018a, 2018b). An upper atmosphere nuclear detonation designed to generate an electromagnetic pulse effect is just such an example (McKown, 2019)."

Electromagnetic pulse effects extend to the tangent point, inflicting disruptive effects on the cities of Vladivostok, Kitakyushu, and Beijing. Distances from Pyongyang, North Korea (kilometers, sm): Seoul (194, 120), Busan (517, 321), Vladivostok (686, 426), Kitakyushu (730, 454), Beijing Municipality $(812,505)$ (Distance from Pyongyang to ...., n. d.). Spacecraft with large solar arrays, like the International Space Station, Milstar, and AEHF NC2 constellations start to twist in response to radiation-induced torques. In the aftermath, the United Nations Security Council looks to 'charge' the North Korean leadership with a treaty violation or lodge a liability complaint. Sadly, they struggle to find grounds to do so.

The doomsday scenario of an adversary employing a high-altitude electromagnetic pulse over the central continental United States may be so escalatory that it merits less consideration unless coupled to a discussion of existential threats. The above exploration may warrant additional contemplation, whether for additional jurisprudence, for intelligence indicators and warning, for electromagnetic pulse effects modeling and simulation, and for deterrence theory and messaging. Until then, be wary of the use of nuclear weapons to cause degradation of systems and contest the celestial lines of communications by means of distant blocking from within the sovereign territory of one's adversary. As of this writing, the University of Adelaide is leading efforts to develop a comprehensive examination of and codification of law, the use of force by states, and the law of armed conflict as they apply to outer space. The Woomera Manual on the International Law of Military Space Operations will become the definitive document on military and security law as it applies to space. The project will be completed in 2020 (Graham \& Pry, 2017).

\subsection{Future Research: Resiliency to Deleterious Effects of Electromagnetic Pulse}

Recent research (Zhou, Shi, Bian, \& Zhou, 2019; Rodriguez, 2017; Sands, 2020; Zhang, Li, Qi, Liu, Song, \& Wang, 2018; Lobo, Lang, Starks, \& Sands, 2018; Kim \& Jeong, 2019; Sands, 2019; Baker, Cooper, Heidlauf, \& Sands, 2018; Lee, Park, Singh, Choi, Mandal, Jang, \& Yang, 2020 Lee, Choe, Baek, Singh, \& Ismail, 2017; Sands, 2017; Amore, Boyd, \& Francisco, 2017; Glazunov, Vorobyeva, Vdovin, \& Slepkov, 2019; Gaynutdinov \& Chermoshentsev, 2016; Sands, Kim, \& Agrawal, 2009; Tony \& Sadeghpour, 2013; He \& Cai, 2019; Sands, Kim, \& Agrawal, 2007; Walter, Nunnenkamp, \& Bruder, 2014; Baker, Cooper, Heidlauf, \& Sands, 2018; Smeresky, Rizzo, \& Sands, 2020; Sands, Kim, \& Agrawal, 2012; Hall \& Sands, 2020) into van der Pol equations and deterministic artificial intelligence stemming from a genesis in nonlinear adaptive control has investigated resiliency and two in particular (Sands, 2017; Cooper, Heidlauf, \& Sands, 2017) evaluate representative timing circuits for nuclear command and control systems vis a vis the van der Pol circuit in equation (1) whose unforced nature is depicted in figure 4a. Notice regardless the initial voltage condition, the circuit quickly follows the "limit cycle" trajectory, a natural inherent dynamic of the differential equation governing the circuit's voltage behavior. The circuit is an effective timing circuit due to this inherent dynamic, in that regardless the condition the voltage will follow this natural trajectory establishing a fixed time for voltage to oscillate back to a specified value. These circuits can be upset by impingement of large voltages and currents from electromagnetic pulses as described in (Zhou, Shi, Bian, \& Zhou, 2019). A key finding was that location in the limit cycle of impingement determines the disparate impact on the timing circuit, since the circuit quickly returns to the limit cycle with a displaced progress on the limit cycle. Examine figure $4 \mathrm{a}$ and consider how trajectory deviations result in disparate impact in disparate dependent upon the location along the trajectory of impingement of voltage spikes from electromagnetic pulses. If the impingement on the circuit results in enough interruption in timing, the result is called a "mission kill" in that network synchronization might be no longer possible.

$$
\frac{d^{2} x}{d t^{2}}-\mu\left(1-x^{2}\right) \frac{d x}{d t}+x=0
$$

Cooper, et al. (2017) illustrated the ability to leverage the inherent dynamic together with deterministic artificial intelligence (Sands, 2020; Zhang, Li, Qi, Liu, Song, \& Wang, 2018; Lobo, Lang, Starks, \& Sands, 2018; Kim \& Jeong, 2019; Sands, 2019; Baker, Cooper, Heidlauf, \& Sands, 2018; Lee, Park, Singh, Choi, Mandal, Jang, \& Yang, 2020; Lee, Choe, Baek, Singh, \& Ismail, 2017; Sands, 2017; Amore, Boyd, \& Francisco, 2017; Glazunov, Vorobyeva, Vdovin, \& Slepkov, 2019; Gaynutdinov \& Chermoshentsev, 2016; Sands, Kim, \& Agrawal, 2009; Tony \& Sadeghpour, 2013; He \& Cai, 2019; Sands, Kim, \& Agrawal, 2007; Walter, Nunnenkamp, \& Bruder, 2014; Baker, Cooper, Heidlauf, \& Sands, 2018; Smeresky, Rizzo, \& Sands, 2020) methods to drive the circuit's limit 
cycle be a perfect circle utilizing equation (2).

$$
\frac{d^{2} x}{d t^{2}}-\mu\left(1-x^{2}\right) \frac{d x}{d t}+x=\mathrm{F}(\mathrm{t}) \equiv \frac{d^{2} x_{d}}{d t^{2}}-\mu\left(1-x_{d}^{2}\right) \frac{d x_{d}}{d t}+x_{d}
$$

This should imply consistent deleterious effects regardless of the location along the limit cycle trajectory the impingement occurs. This should produce consistent limiting values of timing circuit vulnerability, eliminating the complicating factor of time-of-impingement along the limit cycle. Immediate research has commenced by the corresponding author in this regard. Examine figure $4 \mathrm{~b}$ (after the initial transients), progress along the perfect circle would imply very predicable timing differences due to the symmetry of the trajectory.

Amore, et al. applied the Lindstedt-Poincar'e method (Sands, 2017) to study the limit cycle of oscillations and claim to have drastically improved all previous results obtained. They utilized Hermite-Pad'e approximants to describe series bifurcation and claim unprecedented accuracy (100 digits). Meanwhile, Gaynutdinov, et al. (2016) showed a reduction in the quality of the electronic system functioning when subjected to intentional ultrashort electromagnetic pulses. Tony, et al., (2013) investigated quantum fluctuations affect phase locking synchronization of van der Pol oscillators with trapped ions. Walter, et al. (2014) studied synchronization of two dissipative, coupled Van der Pol oscillators where strict frequency locking is prevented by noise, replaced by a crossover from weak to strong frequency entrainment. Importantly, they discuss the behavior of an oscillator subject to an external drive, which is important to future efforts to use deterministic artificial intelligence to drive the circuit in order to maintain a symmetric, circular phase portrait seeking normalized behavior following an electromagnetic pulse. Moreover, they describe experimental realization of two coupled quantum van der Pol oscillators in an optomechanical setting. Following the immediate research in circularizing the phase portrait to normalize circuit deleterious effects, recent results (Sands, 2017; Sands, Kim, \& Agrawal, 2012) should be leveraged to investigate impacts on circuits with encryption.

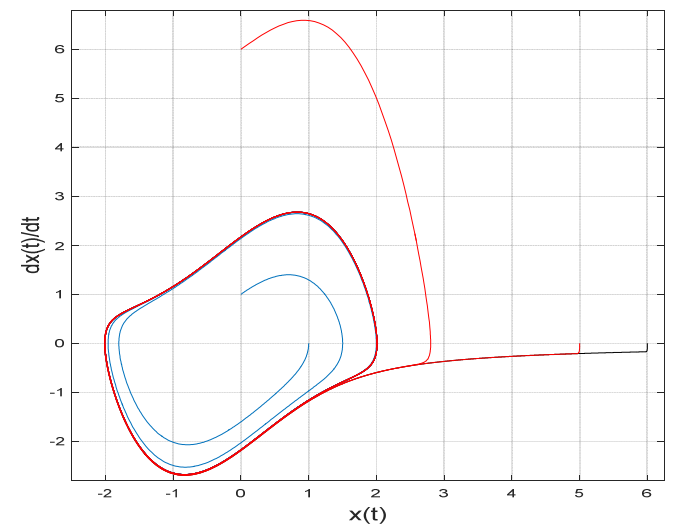

(a) Voltage and rate forward time-propagated nonlinear, unforced van der Pol equation (1).

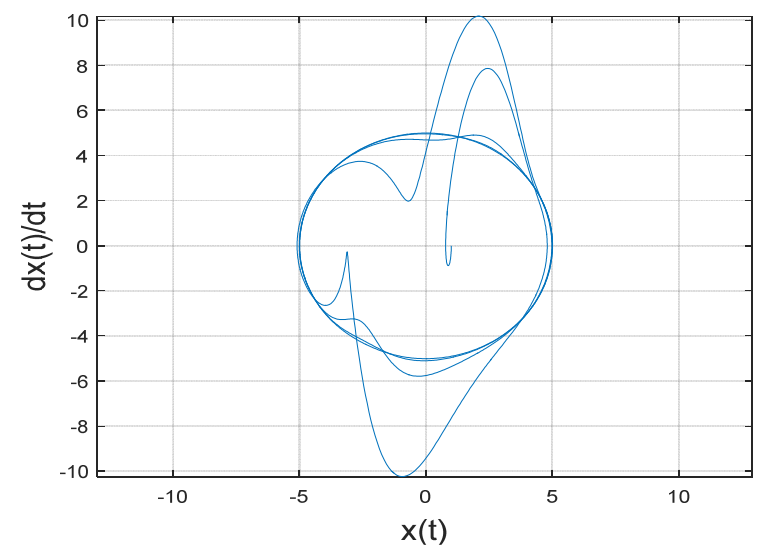

(b) Voltage and rate forward time-propagated nonlinear, ideally forced nonlinear, unforced van der Pol equation commanding a desired circular trajectory per equation (2) with radius five.

Figure 4. Nuclear command and control circuit voltage and voltage rate for van der Pol equation in the cased of unforced (sub-figure a) and forced by the self-awareness assertion of deterministic artificial intelligence (subfigure b)

Some devices are developed to absorb the radiation from the wireless devices (Hasan, Faruque, \& Islam, 2017a, b, c, d; 2018a, b; Hasan, Faruque, S. S Islam, \& M. T. Islam, 2016) metamaterial being one of them metamaterial structure and absorption phenomena of electromagnetic radiation. Investigations of utilization of such materials should be addressed as it applies to the expressions in this manuscript.

This research was independently pursued by the authors, but the genesis of the intellectual property was a graduate course in the U.S. Air Force nuclear enterprise's distance learning education program (Sands, Camacho, \& Mihalik, 2017) in response to an increased need for critical thinking in the nuclear enterprise (Mihalik, Camacho, \& Sands, 2018) in a period of global uncertainty (Bittick \& Sands, 2019; Sands, 2016; Kuklinski, Mitchell, \& Sands, 2020). 


\section{Acknowledgments}

This research was independently pursued by the authors, but the genesis of the intellectual property was a graduate course whose (two-thousand five-hundred dollars) tuition was funded by the U.S. Air Force nuclear enterprise's distance learning education program. The APC was funded by the corresponding participant, Timothy Sands (T.S.) who is not a tenured faculty member of Columbia University. While he is currently a professor at Cornell university, during the period of this research he was the Associate Dean of the Naval Postgraduate School's Graduate School of Engineering and Applied Sciences. Upon the advice of Naval legal counsel, in order to avoid legal jeopardy, T.S. publishes government-funded research under his association with the Naval Postgraduate School, while publishing non-government funded research under his continuing associations with Stanford and Columbia Universities. Conceptualization, M.D.; methodology, M.D.; formal analysis, M.D.; investigation, M.D.; supervision, M.C.; validation, M.C.; resources, T.S.; data curation, M.D.; writing — original draft preparation, M.D.; writing - review and editing, T.S.; funding acquisition, T.S. Please turn to the CRediT taxonomy for the term explanation. Authorship has been limited to those who have contributed substantially to the work reported. All authors have read and agreed to the published version of the manuscript. such as if authors contributed equally to the study. End this paragraph with thanks for personal assistance, such as in manuscript preparation.

\section{Conflict of interests}

The authors declare that there is no conflict of interests regarding the publication of this paper.

\section{References}

Amore, P., Boyd, J. P., \& Francisco, M. F. (2017). High order analysis of the limit cycle of the van der Pol Oscillator. J. Math. Phys., 59(1). Retrieved from https://arxiv.org/pdf/1711.09978.pdf; https://doi.org/10.1063/1.5016961

Baker, K., Cooper, M., Heidlauf, P., \& Sands, T. (2018). Autonomous Trajectory Generation for Deterministic Artificial Intelligence. Elec. Electron. Eng., 8(3), 59-68.

Baker, K., Cooper, M., Heidlauf, P., \& Sands, T. (2018). Autonomous trajectory generation for deterministic artificial intelligence. Electr. Electron. Eng., 8, 59.

Bittick, L., \& Sands, T. (2019). Political Rhetoric or Policy Shift: A Contextual Analysis of the Pivot to Asia. $J$. Soc. Sci., 15, 92. https://doi.org/10.3844/jssp.2019.92.125

Blake, D., \& Vihul, L. (Eds). (2018). The Woomera manual on the international law of military space operations. The Published October 2018 as document ID CRICOS 00123M by University of Adelaide. Retrieved from https://law.adelaide.edu.au/woomera/system/files/docs/Woomera\%20Manual.pdf

Commission to Assess the Threat to the United States from Electromagnetic Pulse Attack Washington United States. (2017). Assessing the Threat from Electromagnetic Pulse (EMP). Defense Technical Information Center, Fort Belvoir.

Compton Effect. (n. d.). Retrieved from https://www.radioactivity.eu.com/site/pages/Compton_Effect.htm

Cooper, M., Heidlauf, P., \& Sands, T. (2017). Controlling Chaos-Forced van der Pol Equation. Mathematics, 5, 70. https://doi.org/10.3390/math5040070

Distance from Pyongyang to .... Retrieved from http://www.timeanddate.com

Electromagnetic Pulse: Effects on the U.S. Power Grid. (n. d.). Retrieved from https://www.ferc.gov/industries/electric/indus-act/reliability/cybersecurity/ferc_executive_summary.pdf

Gaynutdinov, R. R., \& Chermoshentsev, S. F. (2016). Immunity research of the electronic systems elements at the influence of intentional electromagnetic pulses. 17th International Conference of Young Specialists on Micro/Nanotechnologies and Electron Devices EDM (pp. 214-218). https://doi.org/10.1109/EDM.2016.7538727

Glasstone, S. (2009). The Effects of Nuclear Weapons. Knowledge Publications: Turtle Creek USA. ISBN: 9781603220163

Glasstone, S., \& Dolan, P. J. (Eds.). (1977). United States Department of Defense and the United States Department of Energy, The Effects of Nuclear Weapons (3rd ed.).

Glazunov, P., Vorobyeva, E., Vdovin, V., \& Slepkov, A. (2019). Numerical modeling of the influence of electromagnetic pulses on the operation of typical electronic self-oscillating systems. J. Rad. Elect., 11 . Retrieved from http://jre.cplire.ru/jre/nov19/20/text.pdf; https://doi.org/10.30898/1684-1719.2019.11.20

Gordon, G., \& Morgan, W. (1993). Principles of Communications Satellites. New York: John Wiley \& Sons, Inc. 
Graham, W. (2008). Commission to Assess the Threat to the United States from Electromagnetic Pulse (EMP) Attack. House Armed Services Committee, Washington.

Graham, W., \& Pry, P. (2017). Empty Threat or Serious Damage: Assessing North Korea's Risk to the Homeland. Testimony to the U.S. House of Representatives Committee on Homeland Security, Subcommittee on Oversight and Management Efficiency Hearing.

Hall, D., \& Sands, T. (2020). Quantum Cryptography for Nuclear Command and Control. Comp. Info. Sci., 13(1), 72. https://doi.org/10.5539/cis.v13n1p72

Harrington, A. (2020). Private communications.

Hasan, M. M., Faruque, M. R. I., \& Islam, M. T. (2017a). A Mirror Shape Chiral Meta Atom for C-Band Communication. IEEE Access, 5, 21217-21222. https://doi.org/10.1109/ACCESS.2017.2677463

Hasan, M. M., Faruque, M. R. I., \& Islam, M. T. (2017b). A single layer negative index meta atom at microwave frequencies. Microw Opt Technol Lett, 59(6) 1450-1454. https://doi.org/10.1002/mop.30566

Hasan, M. M., Faruque, M. R. I., \& Islam, M. T. (2017c). A tri-band microwave perfect metamaterial absorber. Micro. Opt. Tech. Let., 59, 2302-2307. https://doi.org/10.1002/mop.30726

Hasan, M. M., Faruque, M. R. I., \& Islam, M. T. (2017d). Compact Left-Handed Meta-Atom for S-, C- and KuBand Application. Appl. Sci., 7, 1071. https://doi.org/10.3390/app7101071

Hasan, M. M., Faruque, M. R. I., \& Islam, M. T. (2018a). Dual Band Metamaterial Antenna For LTE/Bluetooth/WiMAX System. Sci Rep, 8, 1240. https://doi.org/10.1038/s41598-018-19705-3

Hasan, M. M., Faruque, M. R. I., \& Islam, M. T. (2018b). Tree-shaped fractal meta-surface with left-handed characteristics for absorption application. Appl. Phys., A 124, 127. https://doi.org/10.1007/s00339-017-14989

Hasan, M. M., Faruque, M. R. I., Islam, S. S., \& Islam, M. T. (2016). A New Compact Double-Negative Miniaturized Metamaterial for Wideband Operation. Materials, 9, 830. https://doi.org/10.3390/ma9100830

He, J., \& Cai, J. (2019). Design of a New Chaotic System Based on Van Der Pol Oscillator and Its Encryption Application. Mathematics, 7(8), 743. https://doi.org/10.3390/math7080743

Joint Chiefs of Staff, Joint Publication 3-14: Space Operations. (2018). Department of Defense: Washington.

Karzas, W., \& Latter, R. (1962). Electromagnetic Radiation from a Nuclear Explosion in Space. Physics Review, 126(6), 1919-1926. https://doi.org/10.1103/PhysRev.126.1919

Kim, S., \& Jeong, I. (2019). Vulnerability Assessment of Korean Electric Power Systems to Late-Time (E3) HighAltitude Electromagnetic Pulses. Energies, 12, 3335. https://doi.org/10.3390/en12173335

Klein, J. (2006). Space Warfare: Strategy, Principles and Policy. London: Routledge.

Koplow, D. (2018). The Fault is Not in Our Stars: Avoiding an Arms Race in Outer Space. Harv. Int. Law J., 59(2), 331-388. https://doi.org/10.2139/ssrn.3057583

Koplow, D. (2020). Private communications.

Kuklinski, C., Mitchell, J., \& Sands, T. (2020). Bipolar strategic stability in a multipolar world. J. Pol. Law, 13, 82. https://doi.org/10.5539/jpl.v13n1p82

Lee, H.-S., Choe, H.-B., Baek, I.-Y., Singh, J. K., \& Ismail, M. A. (2017). Study on the Shielding Effectiveness of an Arc Thermal Metal Spraying Method against an Electromagnetic Pulse. Materials, 10, 1155. https://doi.org/10.3390/ma10101155

Lee, H.-S., Park, J.-H., Singh, J. K., Choi, H.-J., Mandal, S., Jang, J.-M., \& Yang, H.-M. (2020). Electromagnetic Shielding Performance of Carbon Black Mixed Concrete with Zn-Al Metal Thermal Spray Coating. Materials, 13, 895. https://doi.org/10.3390/ma13040895

Lobo, K., Lang, J., Starks, A., \& Sands, T. (2018). Analysis of Deterministic Artificial Intelligence for Inertia Modifications and Orbital Disturbance. Int. J. Con. Sci. Eng., 8(3) 53-62.

McKown, L. (2019). Don't Be Caught In the Dark: Examining Deterrence Options for a High Altitude Electromagnetic Pulse Limited Nuclear Attack. The United States Air Force, February 2019. Retrieved from $\mathrm{http}: / / \mathrm{www}$. airuniversity.af.edu/csds/

Ministry of Defence: Electromagnetic Pulse Protection Modules. (n. d.). Retrieved from https://www.pddevices.co.uk/products/ministry-of-defence= 
Morrow-Jones, J. (2019). Nominal High-Altitude Electromagnetic Pulse (HEMP) Waveforms. Retrieved from https://www.aerodefensetech.com/component/content/article/adt/tech-briefs/aerospace/34870

Morrow-Jones, J. (2019). Nominal High-Altitude Electromagnetic Pulse (HEMP) Waveforms. Defense Threat Reduction Agency, Ft. Belvoir.

Mosher, D. (2017). Nuclear bombs trigger a strange effect that can fry your electronics - here's how it works. Retrieved from https://www.businessinsider.com/nukes-electromagnetic-pulse-electronics-2017-5

Nakatani, S., \& Sands, T. (2018). Eliminating the Existential Threat from North Korea. Sci. Tech., 8, 11-16.

NASA. (n. d.). 17. Nuclear Weapon Effects In Space. Retrieved from https://history.nasa.gov/conghand/nuclear.htm

Nominal High-Altitude Electromagnetic Pulse (HEMP) Waveforms. (2019). Technical Report DTRA TR 09-22. Defense Threat Reduction Agency: Fort Belvoir, USA..

Nuclear Threat Initiative, "North Korea Nuclear," NTI.org. (2018). Retrieved from https://www.nti.org/learn/countries/north-korea/nuclear/

Nuclear Threat Initiative. (2014). Design Characteristics of North Korea's Ballistic and Cruise Missiles. Monterey Institute of International Studies. $\quad$ Retrieved from https://media.nti.org/pdfs/design_characteristics_of_north_koreas_ballistic_and_cruise_missiles.pdf

Nuclear Threat Initiative. (2019). North Korea Delivery Systems Missile. NTI.org. Retrieved from https://www.nti.org/learn/countries/north-korea/delivery-systems/

Raloff, J. (1981). EMP Defensive Strategies. Science News, 119(19), 314-5. https://doi.org/10.2307/3965567

Rodriguez, J. (2017). 6 Types of Artificial Intelligence Environments. Medium.com. Retrieved from https://medium.com/@jrodthoughts/6-types-of-artificial-intelligence-environments-825e3c47d998

Sands, T. (2016). Strategies for Combating Islamic State. Soc. Sci., 5, 39. https://doi.org/10.3390/socsci5030039

Sands, T. (2017). Nonlinear-Adaptive Mathematical System Identification. Computation, 5, 47. https://doi.org/10.3390/computation5040047

Sands, T. (2019). Comparison and Interpretation Methods for Predictive Control of Mechanics. Algorithms, 12, 232. https://doi.org/10.3390/a12110232

Sands, T. (Ed.). (2020). Deterministic Artificial Intelligence. IntechOpen: London. ISBN: 978-1-78984-111-4.

Sands, T., \& Armani, C. (2018). Analysis, Correlation, and Estimation for Control of Material Properties. J. Mech. Eng. Autom, 8, 7-31.

Sands, T., \& Mihalik, R. (2016). Outcomes of the 2010 \& 2015 Nonproliferation Treaty Review Conferences. World J. Soc. Sci. Human, 2, 46.

Sands, T., Camacho, H., \& Mihalik, R. (2017). Education in Nuclear Deterrence and Assurance. J. Def. Manag., 7. https://doi.org/10.4172/2167-0374.1000166

Sands, T., Camacho, H., \& Mihalik, R. (2018). Continuum of Learning: Combining Education, Training, and Experiences. Education, 8, 9-13.

Sands, T., Camacho, H., \& Mihalik, R. (2018a). Nuclear Posture Review: Kahn Vs. Schelling...and Perry. J. Soc. Sci., 14, 145. https://doi.org/10.3844/jssp.2018.145.154

Sands, T., Camacho, H., \& Mihalik, R. (2018b). Theoretical Context of the Nuclear Posture Review. J. Soc. Sci., 14, 124. https://doi.org/10.3844/jssp.2018.124.128

Sands, T., Kim, J. J., \& Agrawal, B. N. (2007). Spacecraft fine tracking pointing using adaptive control. In Proceedings of the 58th International Astronautical Congress, Hyderabad, India; International Astronautical Federation: Paris, France.

Sands, T., Kim, J. J., \& Agrawal, B. N. (2009). Improved Hamiltonian adaptive control of spacecraft (pp. 1-10). In Proceedings of the IEEE Aerospace, Big Sky, MT, USA; IEEE Publishing: Piscataway, NJ, USA. https://doi.org/10.1109/AERO.2009.4839565

Sands, T., Kim, J. J., \& Agrawal, B. N. (2012). Spacecraft Adaptive Control Evaluation (pp. 2012-2476). In Proceedings of the Infotech@ Aerospace, Garden Grove, CA, USA; American Institute of Aeronautics and Astronautics: Reston, VA, USA. https://doi.org/10.2514/6.2012-2476 
Seiler, W. (1975). A Calculational Model for High Altitude EMP. Published by Air Force Institute of Technology: Dayton, USA. Retrieved from https://archive.org/details/DTIC_ADA009208/mode/2up

Smeresky, B., Rizzo, A., \& Sands, T. (2020). Optimal Learning and Self-Awareness Versus PDI. Algorithms, 13, 23. https://doi.org/10.3390/a13010023

Tannenwald, N. (1999). The Nuclear Taboo: The United States and the Normative Basis of Nuclear Non-Use. Int. Org., 53(3), 433-468. Retrieved from http://www.jstor.org/stable/2601286; https://doi.org/10.1162/002081899550959

Tannenwald, N. (2018a). How Strong Is the Nuclear Taboo Today? Wash. Quar., 41(3), 89-109. https://doi.org/10.1080/0163660X.2018.1520553

Tannenwald, N. (2018b). The Vanishing Nuclear Taboo? How Disarmament Fell Apart. For. Aff. Retrieved from https://www.foreignaffairs.com/articles/world/2018-10-15/vanishing-nuclear-taboo

Testimony of Dr. George H. Baker, Senior Advisor to the Congressional EMP Commission at the June 22, 2017 Reliability Technical Conference before the Federal Energy Regulatory Commission. (2017). Retrieved from https://www.ferc.gov/CalendarFiles/20170717080646-Baker,\%20EMP\%20Commission.pdf

The United Nations, Convention on the Prohibition of Military or any Hostile Use of Environmental Modification Techniques. (1977). Geneva: European Union.

The Wommera Manual, University of Adelaide Faculty of the Professions. (2020). Retrieved from https://youtu.be/DTpMwAw_Ga8

Timmerman, K. (2001). U.S. Threatened with EMP Attack. Insight on the News. Retrieved from http://www.insightmag.com/news/2001/05/28/InvestigativeReport/U.Threatened.With.Emp.Attack210973.shtml

Tony, E. L., \& Sadeghpour, H. R. (2013). Quantum synchronization of quantum van der Pol oscillators with trapped ions. Phys. Rev. Let., 111(23), 6. Retrieved from https://arxiv.org/pdf/1306.6359.pdf; https://doi.org/10.1103/PhysRevLett.111.234101

United States Government Accountability Office. (n. d.). GAO Report 18-67: Critical infrastructure protection. Retrieved from https://www.gao.gov/assets/690/689921.pdf

University of Adelaide, "The Woomera Manual (/WOOMERA/)". (2018). Retrieved from http://law.adelaide.edu.au/woomera/

Walter, S., Nunnenkamp, A., \& Bruder, C. (2014). Quantum synchronization of two Van der Pol oscillators. Annalen Der Physik, 527(1), 131-138. Retrieved from https://arxiv.org/abs/1406.7134; https://doi.org/10.1002/andp.201400144

Wei, H., \& Kiang, J. (2016). Simulation of High-Altitude Electromagnetic Pulse (HEMP) above Sea Surface. Progress in Electromagnetic Research, 50, 195-204. https://doi.org/10.2528/PIERM14081902

Wilson, C. (2008). High Altitude Electromagnetic Pulse (HEMP) and High Power Microwave (HPM) Devices: Threat Assessments. Washington: Congressional Research Service.

Yeaw, C. (2015). Prepared Statement for the U.S.-China Economic and Security Review Commission Hearing on China's Offensive Missile Forces. Washington, D.C. Retrieved from https://www.uscc.gov/sites/default/files/Yeaw\%20USCC\%20Testimony\%201\%20Apr\%202015.pdf

Zhang, G., Li, W., Qi, L., Liu, J., Song, Z., \& Wang, J. (2018). Design of Wideband GHz Electric Field Sensor Integrated with Optical Fiber Transmission Link for Electromagnetic Pulse Signal Measurement. Sensors, 18, 3167. https://doi.org/10.3390/s18093167

Zhou, Q., Shi, Y., Bian, X., \& Zhou, B. (2019). Simulation and Protection of Lightning Electromagnetic Pulse in Non-Metallic Nacelle of Wind Turbine. Energies, 12, 1745. https://doi.org/10.3390/en12091745

\section{Copyrights}

Copyright for this article is retained by the author(s), with first publication rights granted to the journal.

This is an open-access article distributed under the terms and conditions of the Creative Commons Attribution license (http://creativecommons.org/licenses/by/4.0/). 